\title{
pH-Induced Electrostatic Interaction between Polyacrylates and Amino-Functionalized Graphene Oxide on Stability and Coating Performances
}

\author{
Wenbo Zhang ${ }^{1,2, *}$, Sichun $\mathrm{Li}^{2}$, Jianzhong $\mathrm{Ma}^{3, *}$, Yingke $\mathrm{Wu}^{3}$, Chao Liu ${ }^{1,2}$ and Hongxia Yan ${ }^{4}$ \\ 1 Shaanxi Collaborative Innovation Center of Industrial Auxiliary Chemistry and Technology, \\ Shaanxi University of Science and Technology, Xi'an 710021, China; lc1010158@163.com \\ 2 College of Chemistry and Chemical Engineering, Shaanxi University of Science and Technology, \\ Xi'an 710021, China; L15191562651@163.com \\ 3 College of Bioresources Chemical and Materials Engineering, Shaanxi University of Science and Technology, \\ Xi'an 710021, China; einske@163.com \\ 4 School of Chemistry and Chemical Engineering, Northwestern Polytechnical University, Xi'an 710129, China; \\ hongxiayan@nwpu.edu.cn \\ * Correspondence: zhangwenbo@sust.edu.cn (W.Z.); majz@sust.edu.cn (J.M.)
}

Citation: Zhang, W.; Li, S.; Ma, J.; Wu, Y.; Liu, C.; Yan, H. pH-Induced Electrostatic Interaction between Polyacrylates and AminoFunctionalized Graphene Oxide on Stability and Coating Performances. Polymers 2021, 13, 3406. https:// doi.org/10.3390/polym13193406

Academic Editor: Ioan Botiz

Received: 19 August 2021

Accepted: 28 September 2021

Published: 3 October 2021

Publisher's Note: MDPI stays neutral with regard to jurisdictional claims in published maps and institutional affiliations.

Copyright: () 2021 by the authors. Licensee MDPI, Basel, Switzerland. This article is an open access article distributed under the terms and conditions of the Creative Commons Attribution (CC BY) license (https:// creativecommons.org/licenses/by/ $4.0 /)$.

\begin{abstract}
Electrostatic interaction between polymers and nanofillers is of great importance for the properties and design of their composites. Polyacrylates with carboxyl, hydroxyl and acylamino groups were synthesized via emulsion polymerization and marked as P(MMA-BA-AA), P(MMABA-HEA) and P(MMA-BA-AM), respectively. Amino-functionalized graphene oxide (NGO) was prepared by Hoffman rearrangement using GO as the raw material. The polyacrylate composites were prepared by mixing NGO with each of the three kinds of polyacrylate. Effects of $\mathrm{pH}$ and NGO amounts on the properties of polyacrylate composites were studied. It was found that the surface charge of polyacrylate and NGO had the greatest effect on the composite properties. P(MMA-BA$\mathrm{AM}) / \mathrm{NGO}$ was not stable at any $\mathrm{pH}(2-8)$. With the same NGO amount of $0.1 \mathrm{wt} \%$, the toughening effect of NGO on P(MMA-BA-AA) was larger than that on P(MMA-BA-HEA). The break strength of P(MMA-BA-AA)/NGO and P(MMA-BA-HEA)/NGO increased to $5.22 \mathrm{MPa}$ by $47 \%$ and $3.08 \mathrm{MPa}$ by $31 \%$, respectively. NGO could increase the thermal stability of P(MMA-BA-AA) and P(MMA-BAHEA) to different degrees. The polyacrylate film-forming processes were tested, and it showed that NGO influenced polyacrylate through the whole film-forming process. The results provide potential methods for the design of polymer-based nanocomposites.
\end{abstract}

Keywords: graphene oxide; polyacrylate; amino group; surface charge

\section{Introduction}

Polymer based graphene composites is an important application field because graphene could increase the properties of composites such as mechanical properties [1,2], electrical performances [3,4], thermal properties [5,6], barrier properties [7,8], flame retardancy [9,10], biomedical applications [11,12], etc. For example, Vasile et al. [13] functionalized graphene oxide with 2-hydroxyethyl methacrylate (HEMA) to prepare a composite with a poly(propylene fumarate)/poly(ethylene glycol) dimethacrylate (PPF/PEGDMA) matrix. The compressive strength, compressive modulus, morphology, equilibrium water content, degradation and mineralization behavior have been investigated and showed effective support for bone tissue formation. The performances of polymer composites changed greatly by graphene itself or by the synergistic effect of graphene and polymer.

Dispersion of graphene or graphene-based nanomaterials in polymers is a hot topic with which researchers are concerned. It is influenced by the interfacial adhesion or interaction between graphene and polymers. In order to improve the performance of composites, lots of methods have been designed and used. The most common method is to 
graft graphene on a target polymer by covalent bonding. Park et al. [14] conjugated aniline to few-layer graphene via perfluorophenyl azide (PFPA)-mediated coupling chemistry. A subsequent in situ polymerization of aniline gave polyaniline covalently grafted on the few-layer graphene surface. The method can be readily adapted to grow polyaniline or other conducting polymers on these technologically important carbon materials. In the report of Wu et al. [15], polyethylene glycol grafted graphene nanosheets (PEG-g-GO) and poly(vinylidene fluoride)/PEG-g-GO nanocomposites were synthesized by a solution mixing method. Polyethylene glycol, through increasing the insulation capacity and free volume, significantly increased the dielectric permittivity and led to a low loss for the composite.

Surfactants or substances that have good compatibility with both graphene and polymers can also be utilized to improve the interfacial adhesion. Firdaus et al. [16] added dodecylbenzene sulfonic acid (DBSA) surfactant in graphene/polyaniline nanocomposites, which developed a homogenous and uniform dispersion of the graphene filler within the polyaniline matrix. The electrical conductivity and thermal conductivity of the composites increased by $10 \%$ and $6 \%$, respectively, compared with those without DBSA. Li et al. [17] used $\beta$-cyclodextrin $(\beta-C D)$ as the bonding agent with its unique structure to form a supramolecular system with graphene oxide layers. They generated the inclusion compound with aniline monomers via in situ polymerization of polyaniline on the surface of graphene oxide. The obtained reduced graphene oxide/carbon nanodots/polyaniline nanocomposites (RGO@CN/PANI) had satisfied performance for supercapacitors.

Functionalizing graphene with organic chains or polymers that have good compatibility with the target polymer is another effective method. In Wang's work [18], functionalized reduced GO (FRGO) was obtained by solvothermal reduction with sodium borohydride as the reduction agent and ammonia hydroxide as the nitrogen source. FRGO/PANI composites were achieved by synthesizing polyaniline (PANI) with FRGO as a substrate via in situ polymerization. The introduction of amino groups facilitates $\pi-\pi$ conjugation and covalent bonding between FRGO sheets and PANI chains, resulting in an intimate and uniform contact between FRGO sheets and PANI chains. Wang et al. [19] chemically modified GO with cystamine dihydrochloride (CDHC), leading to a tight interaction between graphene and rubber owing to the disulfide bonds in CDHC molecules, which can participate in the vulcanization reaction of rubber through disulfide exchange during thermal processing.

For waterborne polymers, especially for polyacrylate, physical blending is a simple and efficient process to introduce graphene or graphene-based nanomaterials. However, simple blending without further interaction could not improve the properties of the composite to a higher level. In our previous work [20], amino-functionalized graphene oxide (NGO) was prepared by Hoffman rearrangement to make sure that the amino group grafted on GO directly. It was blended with polyacrylate directly without high-temperature curing or additional hot-pressing. The advantage of this method is that the process is simple and feasible, and graphene has no influence on the preparation of polyacrylate. The results showed that the performances of the polyacrylate/NGO composite were improved by simply blending and $\mathrm{pH}$ adjusting. We also [21] prepared a flexible and mechanically robust waterborne polyacrylate/graphene@polydopamine composite by establishing a tough interface through polydopamine modification and $\mathrm{pH}$-triggered hydrogen bonding. By adjusting the initial $\mathrm{pH}$ value in the process of film formation, the electrostatic repulsion between graphene@polydopamine and polyacrylate changed to a hydrogen bond, so as to improve the mechanical properties. Waterborne polyacrylate material has been widely used as a coating agent [22], leather finish [23], biomaterial [24], etc. That means $\mathrm{pH}$-induced interaction between polyacrylate and graphene will significantly change the proportion of the composites.

In the present work, polyacrylate with carboxyl, hydroxyl and acylamino groups was synthesized via emulsion polymerization by introducing the monomers AA, HEA and AM, marked as P(MMA-BA-AA), P(MMA-BA-HEA) and P(MMA-BA-AM), respectively. Polyacrylate with different functional groups will show different surface changes at dif- 
ferent $\mathrm{pH}$. The polyacrylate/NGO composite was prepared by mixing NGO with each of the three kinds of polyacrylate. The effects of different $\mathrm{pH}$ and NGO amounts on the properties of polyacrylate were studied. The interfacial interactions of polyacrylate with different functional groups and NGO were investigated via mechanical tests, zeta potential, thermogravimetric analysis and film form process detection.

\section{Materials and Methods}

\subsection{Materials}

Amino-functionalized graphene oxide (NGO) was prepared by amination of graphene oxide through Hoffman rearrangement. The typical synthesis can be found in our previous work [20]. Methyl methacrylate (MMA), n-butyl acrylate (BA), acrylic acid (AA), hydroxyethyl acrylate (HEA), acrylamide (AM), sodium dodecyl sulfate (SDS), polyethylene glycol-400 (PEG-400, molecular weight $380-430 \mathrm{~g} / \mathrm{mol}$ ), ammonia water $\left(\mathrm{NH}_{3} \bullet \mathrm{H}_{2} \mathrm{O}\right.$, $25-28 \%$, aq.) and ammonium persulfate (APS) were purchased from Sinopharm Chemical Reagent Co., Ltd. All chemicals were used as received without any further purification. Deionized water was used throughout the experiment.

\subsection{Preparation of Polyacrylate with Different Functional Groups}

Polyacrylate compounds containing different functional groups were obtained through emulsion polymerization of MMA, BA and functional monomers (AA, HEA or AM). The processes are presented in Scheme 1. Firstly, SDS (1.00 g), PEG-400 (0.25 g) and deionized water $(71.00 \mathrm{~g})$ were charged in a three-neck bottle with a thermometer, refluxing condensation pipe and stirrer. After the mixture was uniform, MMA $(0.05 \mathrm{~mol}), \mathrm{BA}(0.08 \mathrm{~mol})$ and AA $(0.12 \mathrm{~mol})$ were added and stirred. Then, polymerization was carried out at $80^{\circ} \mathrm{C}$ for $2 \mathrm{~h}$ with dropwise addition of a mixture of monomers (MMA ( $0.10 \mathrm{~mol}), \mathrm{BA}(0.15 \mathrm{~mol})$, AA $(0.02 \mathrm{~mol})$ and APS solution $(30 \mathrm{~g}, 1.6 \%))$. After cooling, polyacrylate materials containing different functional groups were obtained and defined as P(MMA-BA-AA), P(MMA-BAHEA) and P(MMA-BA-AM). The amounts of AM (0.14 mol) and HEA (0.14 mol) were calculated to keep the molar weight the same as AA. That would keep the number of functional groups the same in different polyacrylate preparations.

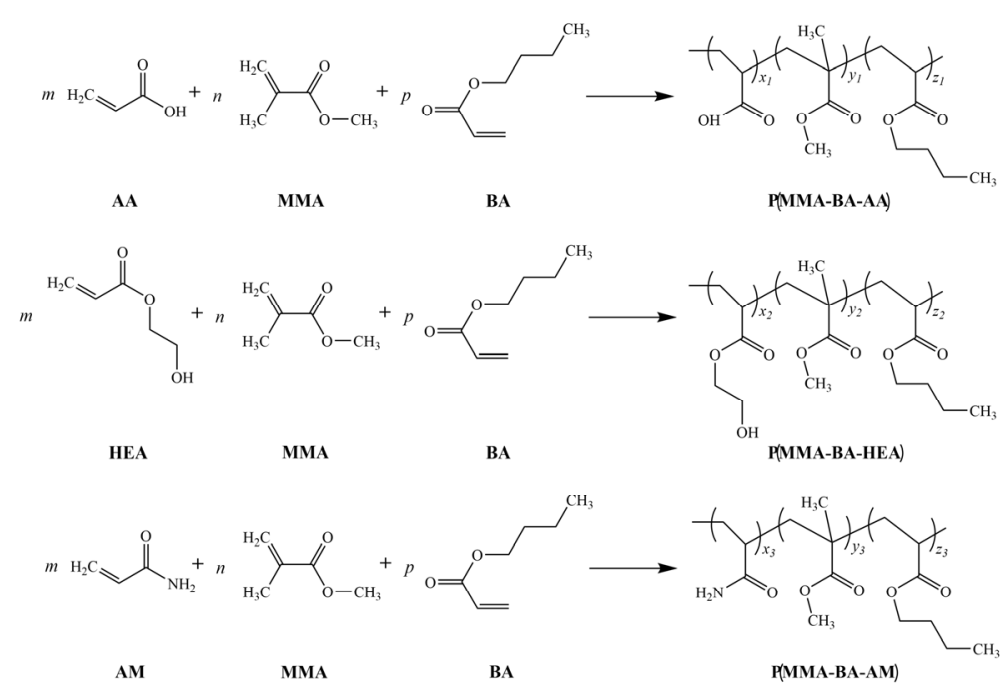

Scheme 1. Schematic illustration for the preparation of polyacrylate.

\subsection{Preparation of Polyacrylate/NGO Composites}

The $\mathrm{pH}$ of $\mathrm{P}(\mathrm{MMA}-\mathrm{BA}-\mathrm{AA})$ was adjusted to different values $(2,4,6,7,8)$ by adding ammonia hydroxide. Then, different amounts of NGO $(0.1-0.7 \mathrm{wt} \%)$, in relation to polyacrylate, were added with the help of magnetic stirring (30 min, $100 \mathrm{rpm}$ ) and ultrasonic processing $(30 \mathrm{~min}, 150 \mathrm{~W}$ ) to obtain a uniform composite material. After that, P(MMA- 
BA-AA)/NGO was prepared. P(MMA-BA-HEA)/NGO and P(MMA-BA-AM)/NGO composite material were prepared by the same procedure.

Films were prepared by naturally drying $12 \mathrm{~g}$ of composite material at $\mathrm{pH} 7 \mathrm{in}$ covered Petri dishes to prevent contamination. All dried films were placed in a desiccator for $24 \mathrm{~h}$ before the next procedures in order to keep moisture the same.

\subsection{Characterization}

For mechanical tests, the films were cut by a dumbbell-shaped sampler into $80 \times 15 \mathrm{~mm}^{2}$ sizes. The bench markers used to measure elongation were $3051 \mathrm{~mm}^{3}$. The precise sizes of the specimens were measured before carrying out each test. The break strength and elongation at break were obtained using a Gotech AI-3000 Servo control tensile testing machine. Each kind of sample was examined three times. The structure of the samples was analyzed via Fourier transform infrared spectroscopy (FT-IR, Bruker Alpha VECTOR-22, GER). Malvern Zetasizer Nano-ZS (Malvern, UK) was used to measure the zeta potential of the polyacrylate material particles (the material was diluted to $1 \%$ in solid content) and NGO aqueous suspensions $(0.1 \mathrm{mg} / \mathrm{mL}$ as described above). The thermal degradation of polyacrylate/NGO composites was investigated using a Q500 thermo-analyzer instrument (TA Instruments, DE, USA). Samples of $\sim 5 \mathrm{mg}$ were heated from 30 to $600{ }^{\circ} \mathrm{C}$ at a linear rate of $10^{\circ} \mathrm{C} / \mathrm{min}$ under nitrogen flow $(50 \mathrm{~mL} / \mathrm{min})$. The samples were kept in a dryer before the thermogravimetric analysis. The effect of NGO on the polyacrylate film-forming process was measured by Horus Coatings Drying (France Formulaction Ltd, TSL, France) to characterize the kinetics. The polyacrylate material was dropped into a groove, which was $5 \mathrm{~mm}$ wide and $500 \mu \mathrm{m}$ deep, at $27^{\circ} \mathrm{C}$ and $22 \% \mathrm{RH}$. The groove was placed under a detector to monitor microstructural changes during the film formation process. A Hitachi $\mathrm{S} 4800$ scanning electron microscope (SEM, Tokyo, Japan) was used to observe the morphologies of polyacrylate/NGO composites.

\section{Results and Discussion}

\subsection{Structural Analysis of Polyacrylate with Different Functional Groups}

The goal of introducing AA, HEA and AM in the polyacrylate emulsion polymerization is to graft carboxyl, hydroxyl and acylamino groups on polyacrylate, respectively. The FT-IR spectra of P(MMA-BA-AA), P(MMA-BA-HEA) and P(MMA-BA-AM) are shown in Figure 1. As for the P(MMA-BA-AA), the absorption peaks that appear at $1164 \mathrm{~cm}^{-1}$ and $1724 \mathrm{~cm}^{-1}$ belong to the stretching vibration of $\mathrm{C}=\mathrm{O}$. The peaks at $3424 \mathrm{~cm}^{-1}$ and $3029 \mathrm{~cm}^{-1}$ belong to the stretching vibration of -OH. For P(MMA-BA-HEA), the band at $3420 \mathrm{~cm}^{-1}$ corresponds to the stretching vibration of $-\mathrm{OH}$. The band at about $2926 \mathrm{~cm}^{-1}$ is assigned to $\mathrm{C}-\mathrm{H}$ stretching vibration, while the band at $1731 \mathrm{~cm}^{-1}$ is attributed to the stretching vibration of $C=O$. For $P(M M A-B A-A M)$, the peaks at $3427 \mathrm{~cm}^{-1}, 3344 \mathrm{~cm}^{-1}$ and $3195 \mathrm{~cm}^{-1}$ are attributed to the stretching vibration of N-H. The band at $1647 \mathrm{~cm}^{-1}$ corresponds to the stretching vibration of $\mathrm{C}=\mathrm{O}$. The absorption peaks that appear at $1546 \mathrm{~cm}^{-1}$ and $1216 \mathrm{~cm}^{-1}$ belong to the stretching vibration of C-N. Therefore, polyacrylates with carboxyl, hydroxyl and acylamino groups were successfully prepared.

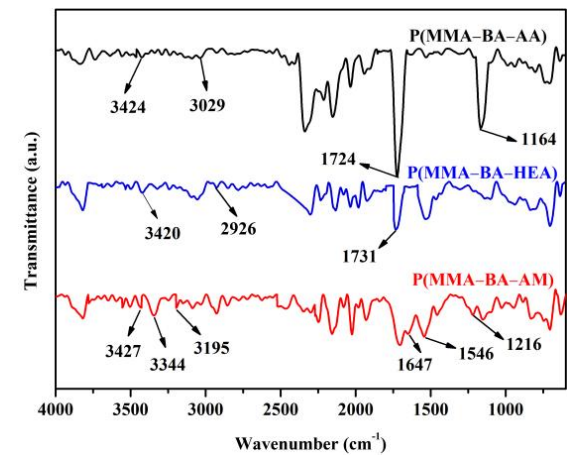

Figure 1. FT-IR spectra of P(MMA-BA-AA), P(MMA-BA-HEA) and P(MMA-BA-AM). 


\subsection{Stability of Polyacrylate/NGO Composite Material}

The amino group in NGO as well as the carboxyl, hydroxyl and acylamino groups on the polyacrylate matrix are all functional groups and sensitive to $\mathrm{pH}$. When mixing NGO with polyacrylate, $\mathrm{pH}$ acts as an important factor in stabilizing NGO in the polymer matrix. Therefore, stability is an important aspect to study in the interaction of NGO and polyacrylate. Table 1 shows the stability of polyacrylate/NGO composites at different $\mathrm{pH}$.

Table 1. Stability of polyacrylate/NGO composite materials at different $\mathrm{pH}$.

\begin{tabular}{cccccc}
\hline pH Value & $\mathbf{2 . 0}$ & $\mathbf{4 . 0}$ & $\mathbf{6 . 0}$ & $\mathbf{7 . 0}$ & $\mathbf{8 . 0}$ \\
\hline P(MMA-BA-AA)/NGO & $\times$ & $\times$ & $\sqrt{ }$ & $\sqrt{ }$ & $\sqrt{ }$ \\
P(MMA-BA-HEA)/NGO & $\times$ & $\times$ & $\sqrt{ }$ & $\sqrt{ }$ & $\sqrt{ }$ \\
P(MMA-BA-AM)/NGO & $\times$ & $\times$ & $\times$ & $\times$ & $\times$ \\
\hline
\end{tabular}

$\sqrt{ }$ means stable, $\times$ means demulsificated.

As shown in Table 1, the polyacrylate/NGO materials present different stabilities as a function of $\mathrm{pH}$. The $\mathrm{P}(\mathrm{MMA}-\mathrm{BA}-\mathrm{AM}) / \mathrm{NGO}$ composite material demulsificated no matter if the $\mathrm{pH}$ value was high or low. When the $\mathrm{pH}$ value was 2 or 4 , the addition of NGO demulsificated the P(MMA-BA-AA)/NGO and P(MMA-BA-HEA)/NGO materials with NGO deposits at the bottom of the glass bottle. With the increase in $\mathrm{pH}$ (higher than 6), the composites became stable (as shown in Figure 2). These phenomena indicate that the dispersion of NGO in the polyacrylate material heavily relies on $\mathrm{pH}$.

(a)
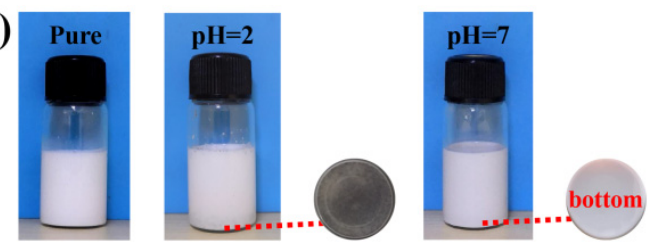

(b)
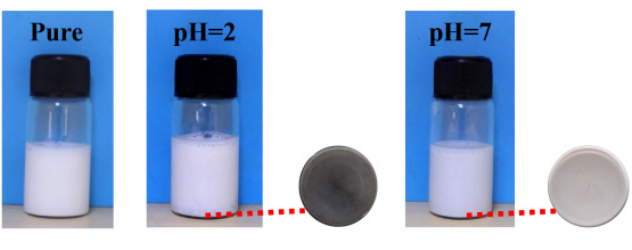

(c)
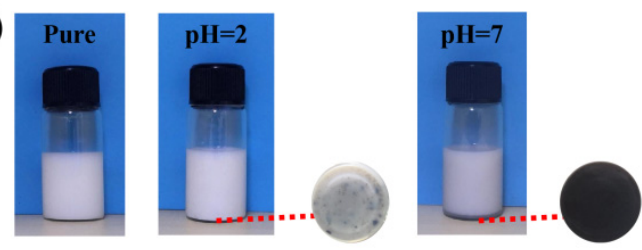

Figure 2. Digital camera photograph of polyacrylate/NGO composite materials at different $\mathrm{pH}$. The circular photo corresponds to the bottom of the glass bottle: (a) P(MMA-BA-AA)/NGO; (b) P(MMA-BA-HEA)/NGO; (c) P(MMA-BA-AM)/NGO.

In order to figure out the reason of different stabilities at different $\mathrm{pH}$ values of the composite material, the zeta potentials of $\mathrm{NGO}$ and polyacrylate material particles were measured via dynamic light scattering (DLS), as shown in Figure 3. It was found that P(MMA-BA-AA), P(MMA-BA-HEA) and P(MMA-BA-AM) material particles were all negatively charged to a different degree when the $\mathrm{pH}$ value was less than 6 , while NGO was positively charged at this $\mathrm{pH}$ range. That means the electrostatic attraction of the opposite charges led NGO to interact with polyacrylate and finally demulsificated the polyacrylate/NGO composite material. 


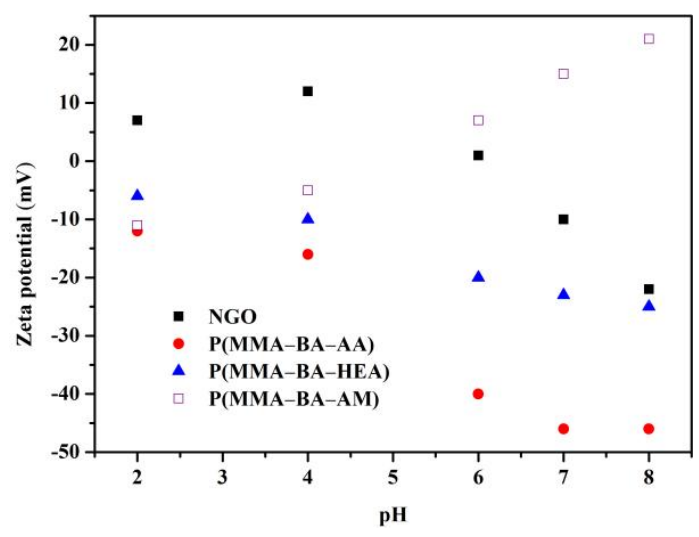

Figure 3. Effect of $\mathrm{pH}$ on the zeta potential of polyacrylate and NGO.

The stability of polyacrylate/NGO at different $\mathrm{pH}$ values is also clearly presented in Scheme 2. NGO was negatively charged when the $\mathrm{pH}$ value was greater than 6 , as the previous work reported [20]. P(MMA-BA-AA) and P(MMA-BA-HEA) were equally negatively charged with NGO. Electrostatic repulsion between NGO and P(MMA-BAAA) or P(MMA-BA-HEA) particles keeps the material stable and NGO finely dispersed. However, the synergistic effect between the $-\mathrm{CONH}_{2}$ group and SDS/PEG-400 on the surface of emulsion particles makes P(MMA-BA-AM) have opposite charges with NGO at any $\mathrm{pH}$ value. Therefore, there is electrostatic attraction between $\mathrm{P}$ (MMA-BA-AM) and NGO. For the emulsion, this electrostatic attraction is not conducive to emulsion stability. That means the P(MMA-BA-AM)/NGO composite material could not be stable within the whole range of measured $\mathrm{pH}$ values.

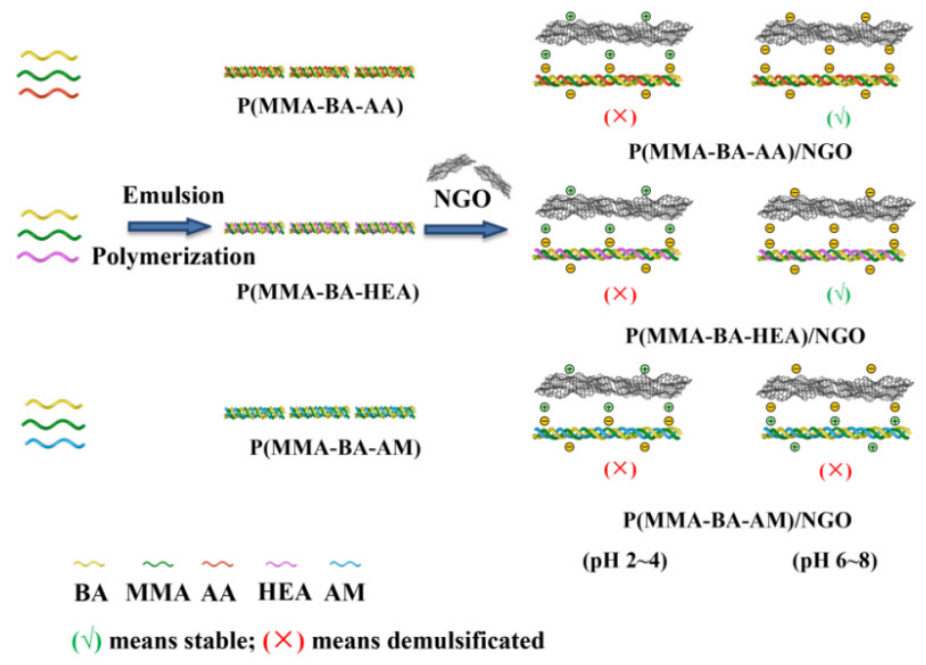

Scheme 2. Schematic illustration for the stability of polyacrylate/NGO composites.

\subsection{Mechanical and Thermal Properties of Polyacrylate/NGO Composite Material}

The goal of incorporating NGO into polyacrylate material is to study the conditions of composite formation and figure out the interactions between the functional groups of NGO and polyacrylate. As described above, P(MMA-BA-AM)/NGO was not stable, so the data could not be presented.

When the $\mathrm{pH}$ of $\mathrm{P}(\mathrm{MMA}-\mathrm{BA}-\mathrm{AA})$ was adjusted to 7 , the maximum amount of NGO that could be mixed into $\mathrm{P}(\mathrm{MMA}-\mathrm{BA}-\mathrm{AA})$ was $0.7 \%$. The mechanical properties of P(MMABA-AA)/NGO films with NGO amounts are shown in Figure 4. As can be seen, the break strength and elongation at break of pure $\mathrm{P}(\mathrm{MMA}-\mathrm{BA}-\mathrm{AA})$ were about $3.54 \mathrm{MPa}$ and $654.4 \%$, respectively. After adding $0.1 \%$ of NGO, the break strength of P(MMA-BA-AA)/NGO increased to $5.22 \mathrm{MPa}$ by $47 \%$, and the elongation at break decreased to $257.9 \%$ by $61 \%$. 
With the NGO amounts continuously increasing, the break strength increased to 6.14 MPa by $73 \%$. However, the increased extent of elongation at break showed minimized change.

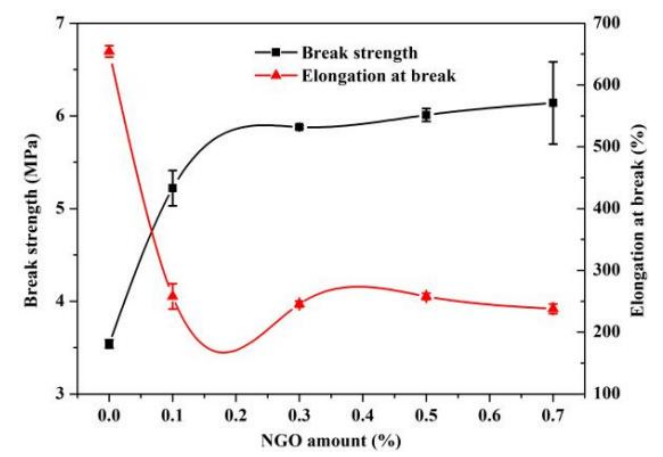

Figure 4. Effect of NGO amounts on mechanical properties of P(MMA-BA-AA)/NGO films.

The situation of polyacrylate with the hydroxyl group, as P(MMA-BA-HEA), was different after adding NGO. When the $\mathrm{pH}$ of $\mathrm{P}(\mathrm{MMA}-\mathrm{BA}-\mathrm{HEA})$ was adjusted to 7, the maximum amount of NGO was $0.5 \%$, as shown in Figure 5. More NGO would precipitate. The break strength and elongation at break of pure P(MMA-BA-HEA) were $2.35 \mathrm{MPa}$ and $731.1 \%$, respectively. After adding $0.1 \%$ of NGO, the break strength of P(MMA-BAHEA)/NGO increased to $3.08 \mathrm{MPa}$ by $31 \%$, and the elongation at break decreased to $650.2 \%$ by $11 \%$. With the NGO amounts increasing, the break strength increased to a maximum of $3.88 \mathrm{MPa}$ by $65 \%$, and elongation at break decreased to $581.4 \%$ by $20 \%$.

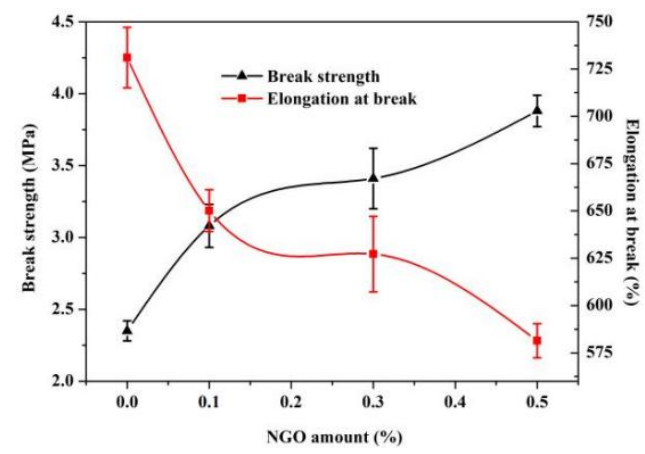

Figure 5. Effect of NGO amounts on mechanical properties of P(MMA-BA-HEA)/NGO films.

As shown in the results above, polyacrylate with the carboxyl group had a stronger interaction with NGO than that of polyacrylate with the hydroxyl group. Firstly, the maximum NGO loading amounts for P(MMA-BA-AA)/NGO and P(MMA-BA-HEA)/NGO were $0.7 \%$ and $0.5 \%$, respectively. Secondly, with the same NGO amount, the increasing rate of break strength of $\mathrm{P}(\mathrm{MMA}-\mathrm{BA}-\mathrm{AA}) / \mathrm{NGO}$ was larger than that of $\mathrm{P}(\mathrm{MMA}-\mathrm{BA}-$ HEA)/NGO, and the rate of decline elongation at break of P(MMA-BA-AA)/NGO was smaller. The increase in break strength was caused by the strengthening effect of graphenebased nanomaterials, as other researchers reported [25-27]. Briefly, the amino group on NGO would have a certain degree of interfacial interaction with carboxyl or hydroxyl groups on polyacrylate. The strength load could transfer from polyacrylate to NGO, so the break strength was reinforced. However, as a stratified material, NGO astricts the molecular entanglement and movement of polyacrylate. The elongation at break was weakened. As is known, the mechanical properties of polymer nanocomposites are significantly affected by the interfacial interaction between fillers and the polymer matrix [28]. As shown in the results, after the polyacrylate films were formed, NGO had a stronger effect with P(MMA-BA-AA) than P(MMA-BA-HEA). This may be caused by the interaction of functional groups of NGO and polyacrylate. 
Testing the change in thermal properties of polymer-based nanocomposites is an effective method to illustrate the interaction of polymers and nanomaterials [29]. Figures 6 and 7 show the TGA curves of polyacrylate and polyacrylate/NGO.

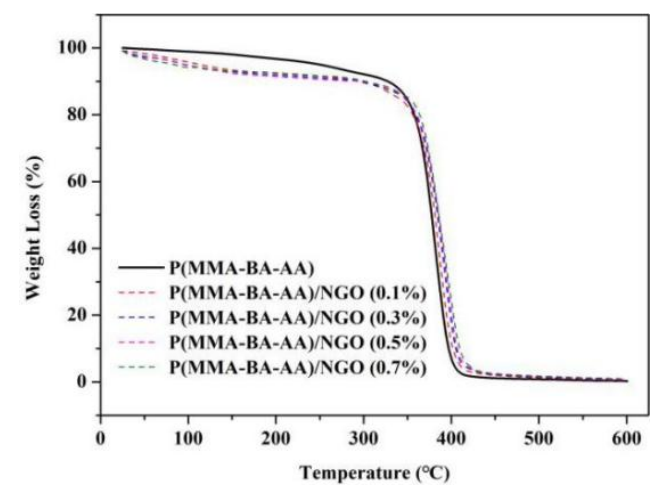

Figure 6. TGA curves of P(MMA-BA-AA)/NGO with different NGO amounts.

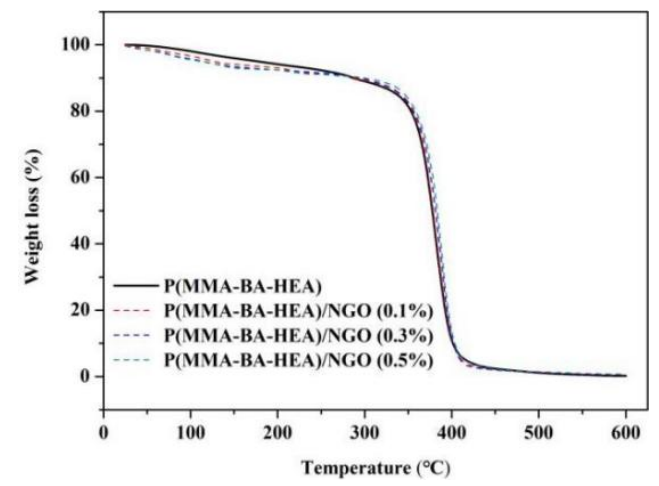

Figure 7. TGA curves of $\mathrm{P}(\mathrm{MMA}-\mathrm{BA}-\mathrm{HEA}) / \mathrm{NGO}$ with different NGO amounts.

According to the study of Xue [30], the thermal weightlessness of GO is divided into two main stages, that is, dehydration and decomposition of oxygen-containing groups. The first stage is observed from $25 \cdot{ }^{\circ} \mathrm{C}$ to $160{ }^{\circ} \mathrm{C}$ with weight loss of $16 \%$ for the dehydration of GO. The second stage is observed from $160{ }^{\circ} \mathrm{C}$ to $240{ }^{\circ} \mathrm{C}$ with a rapid weight loss of $40 \%$ owing to the removal of the oxygen-containing groups. In Figure 6, pure P(MMA-BA-AA) shows one stage of thermal decomposition behavior. That means there was only one inflection point below $400{ }^{\circ} \mathrm{C}$. The maximum decomposition temperature was $381.4^{\circ} \mathrm{C}$. When NGO was added, P(MMA-BA-AA)/NGO decomposed faster than P(MMA-BAAA) below $150{ }^{\circ} \mathrm{C}$. With the increase in NGO content, the decomposition rate was faster, which is related to the amount of adsorbed water released and the amount of NGO. After that, P(MMA-BA-AA)/NGO decomposed slower than P(MMA-BA-AA). As is known, $\mathrm{P}(\mathrm{MMA}-\mathrm{BA}-\mathrm{AA})$ is a hydrophilic polymer. The weight loss that occurred below $150{ }^{\circ} \mathrm{C}$ was associated with the thermal desorption of physically adsorbed and interlamellar water molecules. Because the carboxyl group of $\mathrm{P}(\mathrm{MMA}-\mathrm{BA}-\mathrm{AA})$ interacted with the amino group on NGO, the water loss at $30-150{ }^{\circ} \mathrm{C}$ for $\mathrm{P}(\mathrm{MMA}-\mathrm{BA}-\mathrm{AA}) / \mathrm{NGO}$ may be mostly attributed to physically adsorbed water, and that of P(MMA-BA-AA) was mostly attributed to interlamellar water. It indicated that water had a stronger binding force with P(MMA-BA-AA) than P(MMA-BA-AA)/NGO. That also proved the carboxyl group of $\mathrm{P}(\mathrm{MMA}-\mathrm{BA}-\mathrm{AA})$ interacted with the amino group on NGO. The maximum decomposition temperature of $\mathrm{P}(\mathrm{MMA}-\mathrm{BA}-\mathrm{AA}) / \mathrm{NGO}$ increased as NGO amounts rose. The situations of P(MMA-BA-HEA) and P(MMA-BA-HEA)/NGO were similar as those of P(MMABA-AA) and P(MMA-BA-AA)/NGO. Macrocosmically, NGO could increase the thermal properties of $\mathrm{P}(\mathrm{MMA}-\mathrm{BA}-\mathrm{HEA})$, and the maximum decomposition temperature of $\mathrm{P}(\mathrm{MMA}-$ BA-HEA)/NGO increased as NGO amounts rise. However, the weight loss related to water 
occurred below $140{ }^{\circ} \mathrm{C}$, and the weight loss extent was smaller than that of polyacrylate with the carboxyl group. In order to keep moisture uniform, all samples were placed in a desiccator for $24 \mathrm{~h}$ before the next procedures. Considering this from a thermal analysis perspective, the interaction between the amino group on NGO and carboxyl group of P(MMA-BA-AA) was stronger than that of the amino group on NGO and hydroxy group of P(MMA-BA-HEA).

The morphologies of polyacrylate and polyacrylate/NGO composites are compared in Figure 8. As can be seen from Figure 8 the surfaces of the pure polyacrylates were relatively flat and presented a typical state of polyacrylate emulsion film. When NGO was introduced, the surface of the composite film became rough (as shown in Figure 8(a3,b3)). Under the condition of $\mathrm{pH} 2$, the composites were unstable and dregs appeared. Therefore, the dregs were also observed by SEM. It can be seen from Figure $8(\mathrm{a} 2, \mathrm{~b} 2, \mathrm{c} 2)$ that NGO existed in the dregs, especially in P(MMA-BA-AM)/NGO (Figure 8(c2)). For P(MMA-BA$\mathrm{AM}) / \mathrm{NGO}$, under the condition of $\mathrm{pH} 7$, the composite material cannot be stable in the form of emulsion and would demulsificate. It can also be observed from Figure 8(c3) that NGO was large in size. The above results are consistent with the analysis of zeta potential described earlier.
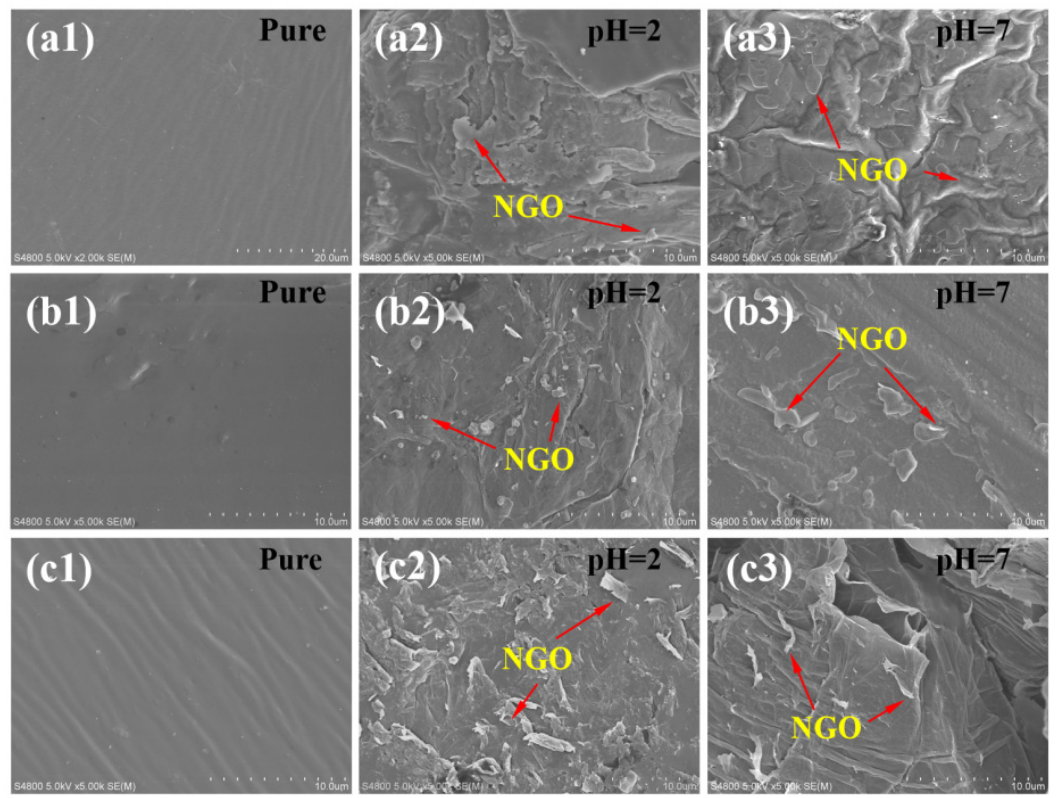

Figure 8. SEM images of (a1) P(MMA-BA-AA) film, P(MMA-BA-AA)/NGO dregs at $\mathrm{pH} 2$ (a2) and film at $\mathrm{pH} 7$ (a3); (b1) P(MMA-BA-HEA) film, P(MMA-BA-HEA)/NGO dregs at $\mathrm{pH} 2$ (b2) and film at pH 7 (b3); (c1) P(MMA-BA-AM) film, P(MMA-BA-AM)/NGO dregs at $\mathrm{pH} 2$ (c2) and pH 7 (c3).

The mechanical properties of polymer nanocomposites are significantly affected by the interfacial interaction between the amino group on NGO and the carboxyl group or hydroxyl group on polyacrylate. To verify the existence of interactions between NGO and P(MMA-BA-AA), P(MMA-BA-HEA) and P(MMA-BA-AM), Materials Studio (MS) 8.0 was used to calculate the binding energy (EBind) between NGO and polymer chains. $\mathrm{C}_{92} \mathrm{O}_{5} \mathrm{~N}_{4} \mathrm{H}_{128}$ was used as the model of NGO. The interaction energy $\left(\mathrm{E}_{\text {Inter }}\right)$ between NGO and different polymer chains was calculated as follows:

$$
\mathrm{E}_{\text {Inter }}=\mathrm{E}_{\mathrm{Total}}-\left(\mathrm{E}_{\mathrm{GNS}}-\mathrm{E}_{\text {Poly }}\right)
$$

where $\mathrm{E}_{\text {Total }}$ is the total energy of each system in equilibrium. $\mathrm{E}_{\mathrm{GNS}}$ and $\mathrm{E}_{\text {Poly }}$ are single point energies of $\mathrm{NGO}$ and polymer chains, respectively. The negative value of $\mathrm{E}_{\text {Inter }}$ was defined as $E_{\text {Bind }}$. As shown in Figure 9 , $E_{\text {Bind }}$ for NGO on P(MMA-BA-AM) was calculated to be $116.92 \mathrm{kcal} / \mathrm{mol}$, which is higher than that of NGO and P(MMA-BA-HEA) 
(67.81 kcal/mol) as well as NGO and P(MMA-BA-AA) $(81.76 \mathrm{kcal} / \mathrm{mol})$. The electrostatic repulsion between $\mathrm{NGO}$ and $\mathrm{P}(\mathrm{MMA}-\mathrm{BA}-\mathrm{AA})$ or $\mathrm{P}(\mathrm{MMA}-\mathrm{BA}-\mathrm{HEA})$ material particles keeps the material stable and NGO finely dispersed.
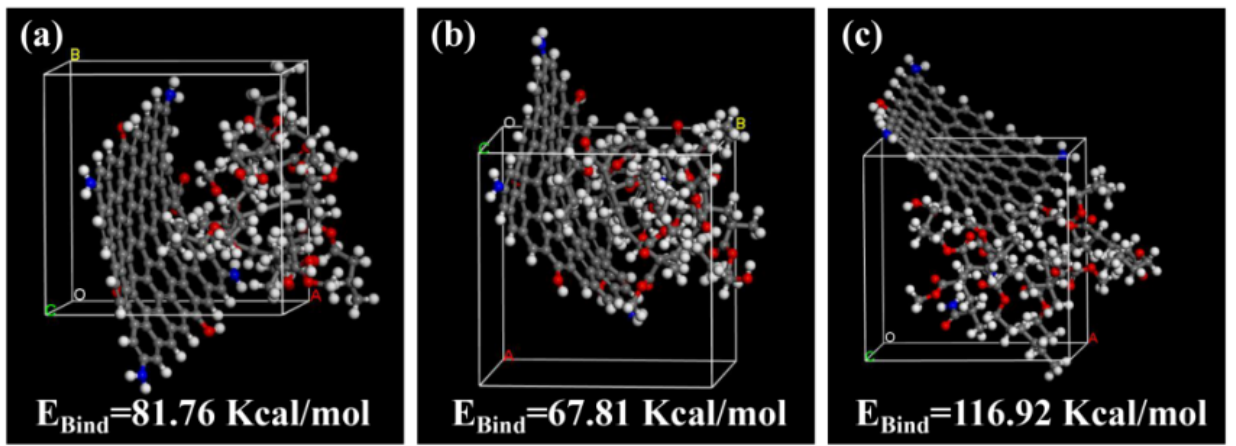

Figure 9. The molecular dynamics simulation of NGO and polymer chains: (a) P(MMA-BA-AA), (b) P(MMA-BA-HEA) and (c) P(MMA-BA-AM).

\subsection{Influence of NGO on Polyacrylate/NGO Composite Film-Forming Processes}

The film-forming process plays a key role on the properties of polyacrylate nanocomposites. To explain the differences observed on the kinetics, the duration was divided into four stages necessary for the sample to turn to dry (Table 2): open time, dust free, set to touch and touch dry, as obtained automatically. In order to study the influence of NGO on the polyacrylate film-forming process, the process was measured by Horus Coatings Drying to characterize the kinetics. The results are shown in Figures 10 and 11. Following Brun [31], the four stages represent the evaporation, particle ordering, particle deformation and interdiffusion of the material. If the evaporation time is too short, it means that the water vapor cannot evaporate sufficiently, which will affect the construction speed. If there is sufficient time in the particle ordering phase, the performance of the resulting film will be improved. The film-forming process of composite material is shown in Scheme 3.

Table 2. The duration of stages for polyacrylate and polyacrylate/NGO material turn to dry.

\begin{tabular}{ccccc}
\hline Samples & Open Time (s) & Dust Free (s) & Set to Touch (s) & Touch Dry (s) \\
\hline P(MMA-BA-AA) & 18 & 71 & 233 & 667 \\
P(MMA-BA-AA)/NGO & 34 & 98 & 134 & 575 \\
P(MMA-BA-HEA) & 21 & 60 & 130 & 714 \\
P(MMA-BA-HEA)/NGO & 39 & 67 & 112 & 608 \\
\hline
\end{tabular}

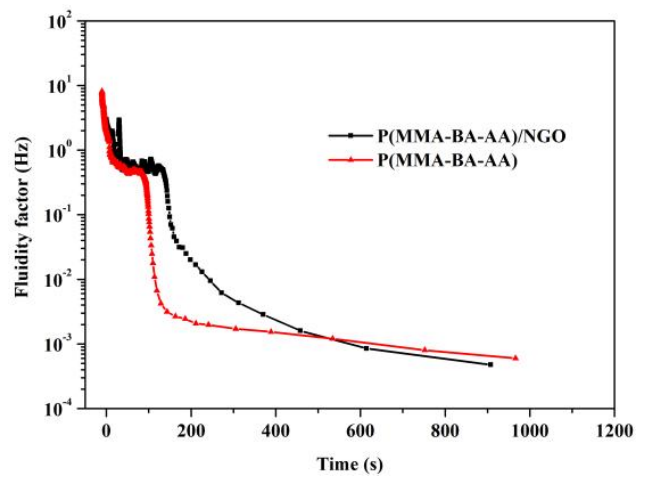

Figure 10. Kinetics of material film-forming processes for P(MMA-BA-AA) and P(MMA-BAAA)/NGO. 


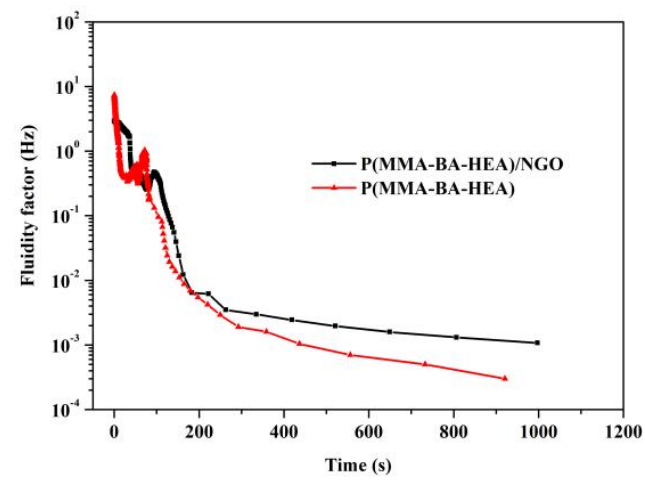

Figure 11. Kinetics of material film-forming processes for P(MMA-BA-HEA) and P(MMA-BAHEA)/NGO.

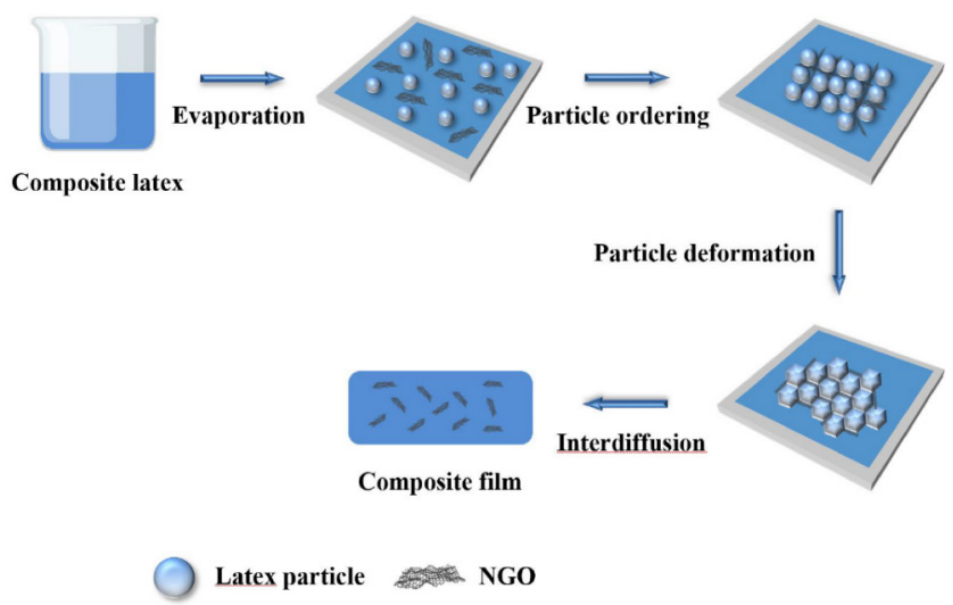

Scheme 3. Schematic illustration for the film-forming process of polyacrylate/NGO composites.

It can be seen from Table 2 that, after NGO was added, evaporation time increased from $18 \mathrm{~s}$ to $34 \mathrm{~s}$. The velocity of water evaporation slowed down because of the barrier effect of the NGO lamellar structure. The particle ordering time increased from $71 \mathrm{~s}$ to $98 \mathrm{~s}$. With the evaporation of water and $\mathrm{NH}_{3} \bullet \mathrm{H}_{2} \mathrm{O}$, the interaction between the carboxyl group of P(MMA$\mathrm{BA}-\mathrm{AA}$ ) and the amino group on NGO changed from electrostatic repulsion to electrostatic attraction. The interaction made the particle ordering time longer. After the relative position of P(MMA-BA-AA) and NGO was steady, the particle deformation time and interdiffusion time decreased by about $100 \mathrm{~s}$. Firstly, movement of the P(MMA-BA-AA) molecular chain would be limited by NGO. Secondly, the water-retaining property of P(MMA-BA-AA) was weakened by the interaction of $\mathrm{P}(\mathrm{MMA}-\mathrm{BA}-\mathrm{AA})$ and NGO. Compared with P(MMA-BAHEA), evaporation time of $\mathrm{P}(\mathrm{MMA}-\mathrm{BA}-\mathrm{HEA}) / \mathrm{NGO}$ increased from $21 \mathrm{~s}$ to $39 \mathrm{~s}$. It was similar to P(MMA-BA-AA)/NGO. The particle ordering time increased from $60 \mathrm{~s}$ to $67 \mathrm{~s}$. The increasing extent was not as much as that of P(MMA-BA-AA)/NGO. In addition, the particle deformation time and interdiffusion time decreased, but the rate of change was lower for P(MMA-BA-AA)/NGO. It proved that the interaction degrees of the functional groups for the two polyacrylate/NGO composites were different. During the film-forming process, the interaction between $\mathrm{P}(\mathrm{MMA}-\mathrm{BA}-\mathrm{AA})$ and NGO was stronger than that of P(MMA-BA-HEA) and NGO.

\section{Conclusions}

Polyacrylate compounds with different functional groups were prepared by introduction of AA, HEA and AM. When NGO was added, $\mathrm{pH}$ had a very important effect on the stability of polyacrylate/NGO composites because different functional groups such as carboxyl, hydroxyl, acylamino and amino groups charged the polyacrylate and NGO 
differently. Furthermore, it influenced the properties of the polyacrylate film. P(MMABA-AM)/NGO was not steady at any $\mathrm{pH}$. P(MMA-BA-AA)/NGO and P(MMA-BAHEA)/NGO were steady when the $\mathrm{pH}$ was greater than 6 . NGO could toughen both P(MMA-BA-AA) and P(MMA-BA-HEA), but the effect of P(MMA-BA-AA)/NGO was better than P(MMA-BA-HEA)/NGO. Combined with the TGA results, the interaction between the amino group on NGO and carboxyl group of P(MMA-BA-AA) was stronger than that of the amino group on NGO and hydroxy of P(MMA-BA-HEA). The kinetics study indicated that NGO influenced polyacrylate through the whole film-forming process.

Author Contributions: Conceptualization, W.Z.; methodology, J.M.; software, Y.W.; validation, S.L., H.Y. and C.L.; formal analysis, W.Z.; investigation, S.L.; resources, W.Z.; data curation, S.L.; writing-original draft preparation, S.L.; writing—review and editing, W.Z.; visualization, S.L.; supervision, W.Z.; project administration, J.M.; funding acquisition, W.Z. All authors have read and agreed to the published version of the manuscript.

Funding: This research was funded by National Natural Science Foundation of China (21908141), Key Research and Development Program of Shaanxi Province (2019GY-171), Scientific Research Project of Shaanxi Provincial Education Department (20JK0527) and Zhejiang Provincial Basic Public Welfare Research Plan Project (LGG21E030003).

Institutional Review Board Statement: Not applicable.

Informed Consent Statement: Not applicable.

Data Availability Statement: The data presented in this study are available on request from the corresponding author.

Conflicts of Interest: The authors declare no conflict of interest.

\section{References}

1. Guo, Y.; Peng, F.; Wang, H.; Huang, F.; Meng, F.; Hui, D.; Zhou, Z. Intercalation polymerization approach for preparing graphene/polymer composites. Polymers 2018, 10, 61. [CrossRef] [PubMed]

2. Jin, Y.; Jing, Y.; Hu, W.; Lin, J.; Cheng, Y.; Yang, X.; Zhang, K.; Lu, C. Regulation mechanism of graphene oxide on the structure and mechanical properties of bio-based gel-spun lignin/poly (vinyl alcohol) fibers. Cellulose 2021, 28, 4745-4760. [CrossRef]

3. Vallés, C.; Zhang, X.; Cao, J.; Lin, F.; Young, R.; Lombardo, A.; Ferrari, A.; Burk, L.; Mülhaupt, R.; Kinloch, I. Graphene/polyelectrolyte layer-by-layer coatings for electromagnetic interference shielding. ACS Appl. Nano Mater. 2019, 2, 5272-5281. [CrossRef]

4. Zhang, W.; Wei, L.; Ma, J.; Bai, S. Exfoliation and defect control of graphene oxide for waterborne electromagnetic interference shielding coatings. Compos. Part A-Appl. Sci. 2020, 132, 105838. [CrossRef]

5. Li, Q.; Tian, X.; Wu, N.; Li, Y.; Pan, T.; Zhang, B.; Duan, Y.; Wang, S.; Li, Y. Enhanced thermal conductivity and isotropy of polymer composites by fabricating 3D network structure from carbon-based materials. J. Appl. Polym. Sci. 2021, 138, 49781. [CrossRef]

6. Wang, L.; Li, H.; Xiao, S.; Zhu, M.; Yang, J. Preparation of p-Phenylenediamine Modified Graphene Foam/Polyaniline@Epoxy Composite with Superior Thermal and EMI Shielding Performance. Polymers 2021, 13, 2324. [CrossRef]

7. Adak, B.; Joshi, M.; Butola, B.S. Polyurethane/functionalized-graphene nanocomposite films with enhanced weather resistance and gas barrier properties. Compos. Part B-Eng. 2019, 176, 107303. [CrossRef]

8. Wang, L.; Zhang, J.; Sun, Y.; Zhang, T.; Wang, L.; Wang, J.; Liang, Y.; Hao, M.; Fu, Q. Green preparation and enhanced gas barrier property of rubber nanocomposite film based on graphene oxide-induced chemical crosslinking. Polymers 2021, $225,123756$. [CrossRef]

9. Wang, G.; Xu, W.; Chen, R.; Li, W.; Liu, Y.; Yang, K. Synergistic effect between zeolitic imidazolate framework-8 and expandable graphite to improve the flame retardancy and smoke suppression of polyurethane elastomer. J. Appl. Polym. Sci. 2020, 137, 48048. [CrossRef]

10. Yao, Y.; Jin, S.; Ma, X.; Yu, R.; Zou, H.; Wang, H.; Lu, X.; Shu, Q. Graphene-containing flexible polyurethane porous composites with improved electromagnetic shielding and flame retardancy. Compos. Sci. Technol. 2020, 200, 108457. [CrossRef]

11. Kumar, S.; Raj, S.; Jain, S.; Chatterjee, K. Multifunctional biodegradable polymer nanocomposite incorporating graphene-silver hybrid for biomedical applications. Mater. Des. 2016, 108, 319-332. [CrossRef]

12. Wang, C.; Jiang, T.; Zhao, K.; Deng, A.; Li, J. A novel electrochemiluminescent immunoassay for diclofenac using conductive polymer functionalized graphene oxide as labels and gold nanorods as signal enhancers. Talanta 2019, 193, 184-191. [CrossRef]

13. Vasile, E.; Pandele, A.; Andronescu, C.; Selaru, A.; Dinescu, S.; Costache, M.; Hanganu, A.; Raicopol, M.; Teodorescu, M. Hema-functionalized graphene oxide: A versatile nanofiller for poly (propylene fumarate)-based hybrid materials. Sci. Rep. 2019, 9, 18685. [CrossRef] [PubMed]

14. Park, J.; Yang, X.; Wickramasinghe, D.; Sundhoro, M.; Orbey, N.; Chow, K.; Yan, M. Functionalization of pristine graphene for the synthesis of covalent graphene-polyaniline nanocomposite. RSC Adv. 2020, 10, 26486-26493. [CrossRef] 
15. Wu, W.; Tu, J.; Li, H.; Zhan, Z.; Huang, L.; Cai, Z.; Li, Q.; Jiang, M.; Huang, J. Suppressed dielectric loss and enhanced thermal conductivity in poly (vinylidene fluoride) nanocomposites using polyethylene glycol-grafted graphene oxide. J. Mater. Sci. Mater. Electron. 2020, 31, 807-813. [CrossRef]

16. Firdaus, S.; Anasyida, A.; Zubir, S.; Mariatti, M. Graphene/polyaniline nanocomposites: Effect of in-situ polymerization and solvent blending methods with dodecylbenzene sulfonic acid surfactant. J. Mater. Sci. Mater. Electron. 2020, 31, 15805-15821. [CrossRef]

17. Li, S.; Gao, A.; Yi, F.; Shu, D.; Cheng, H.; Zhou, X.; He, C.; Zeng, D.; Zhang, F. Preparation of carbon dots decorated graphene/polyaniline composites by supramolecular in-situ self-assembly for high-performance supercapacitors. Electrochim. Acta 2019, 297, 1094-1103. [CrossRef]

18. Wang, Y.; Wang, Y.; Xu, X.; Wang, C. Facile route for the preparation of functionalized reduced graphene oxide/polyaniline composite and its enhanced electrochemical performance. ECS J. Solid. State Sci. 2021, 10, 031003. [CrossRef]

19. Wang, J.; Fei, G.; Pan, Y.; Zhang, K.; Hao, S.; Zheng, Z.; Xia, H. Simultaneous reduction and surface functionalization of graphene oxide by cystamine dihydrochloride for rubber composites. Compos. Part Appl. Sci. 2019, 122, 18-26. [CrossRef]

20. Zhang, W.; Ma, J.; Gao, D.; Zhou, Y.; Li, C.; Zha, J.; Zhang, J. Preparation of amino-functionalized graphene oxide by Hoffman rearrangement and its performances on polyacrylate coating latex. Prog. Org. Coat. 2016, 94, 9-17. [CrossRef]

21. Wei, L.; Ma, J.; Zhang, W.; Bai, S.; Ren, Y.; Zhang, L.; Wu, Y.; Qin, J. pH triggered hydrogen bonding for preparing mechanically strong, electromagnetic interference shielding and thermally conductive waterborne polymer/graphene@ polydopamine composites. Carbon 2021, 181, 212-224. [CrossRef]

22. Yang, Y.; Chen, J.; Ma, G.; Yang, D. Waterborne Cross-Linkable Polyacrylate Latex Coatings with Good Water Resistance and Strength Stabilized by Modified Hectorite. Polymers 2021, 13, 2470. [CrossRef]

23. Bao, Y.; Feng, C.; Wang, C.; Ma, J.; Tian, C. Hygienic, antibacterial, UV-shielding performance of polyacrylate/ZnO composite coatings on a leather matrix. Colloid. Surf. 2017, 518, 232-240. [CrossRef]

24. Garay-Jimenez, J.; Turos, E. A convenient method to prepare emulsified polyacrylate nanoparticles from for drug delivery applications. Bioorg. Med. Chem. Lett. 2011, 21, 4589-4591. [CrossRef]

25. Fan, J.; Yang, J.; Li, H.; Tian, J.; Wang, M.; Zhao, Y. Cryogenic mechanical properties of graphene oxide/epoxy nanocomposites: Influence of graphene oxide with different oxidation degrees. Polym. Test. 2021, 96, 107074. [CrossRef]

26. Wang, G.; Dai, Z.; Liu, L.; Hu, H.; Dai, Q.; Zhang, Z. Tuning the interfacial mechanical behaviors of monolayer graphene/PMMA nanocomposites. ACS Appl. Mater. Int. 2016, 8, 22554-22562. [CrossRef] [PubMed]

27. Alhusaiki-Alghamdi, H. The spectroscopic and physical properties of PMMA/PCL blend incorporated with graphene oxide. Results Phys. 2021, 24, 104125. [CrossRef]

28. Maio, A.; Fucarino, R.; Khatibi, R.; Rosselli, S.; Bruno, M.; Scaffaro, R. A novel approach to prevent graphene oxide re-aggregation during the melt compounding with polymers. Compos. Sci. Technol. 2015, 119, 131-137. [CrossRef]

29. Lee, M.; Wang, T.; Tsai, J. Mechanical properties of nanocomposites with functionalized graphene. J. Compos. Mater. 2016, 23, 54-61. [CrossRef]

30. Mi, X.; Huang, G.; Xie, W.; Wang, W.; Liu, Y.; Gao, J. Preparation of graphene oxide aerogel and its adsorption for $\mathrm{Cu}^{2+}$ ions. Carbon 2012, 50, 4856. [CrossRef]

31. Brun, A.; Dihang, H.; Brunel, L. Film formation of coatings studied by diffusing-wave spectroscopy. Prog. Org. Coat. 2008, 61, 181-191. [CrossRef] 